OPEN ACCESS

Edited by:

Maria Pappas,

Democritus University of Thrace,

Greece

Reviewed by:

Jörg G. Stephan,

Swedish University of Agricultural

Sciences, Sweden

Gerben Messelink,

Wageningen University and Research,

Netherlands

*Correspondence:

Panagiotis G. Milonas p.milonas@bpi.gr

Specialty section:

This article was submitted to Agroecology and Ecosystem Services, a section of the journal

Frontiers in Ecology and Evolution

Received: 03 June 2018 Accepted: 31 December 2018 Published: 17 January 2019

Citation:

Maselou DA, Anastasaki E and Milonas PG (2019) The Role of Host Plants, Alternative Food Resources and Herbivore Induced Volatiles in Choice Behavior of an Omnivorous Predator. Front. Ecol. Evol. 6:241. doi: 10.3389/fevo.2018.00241

\section{The Role of Host Plants, Alternative Food Resources and Herbivore Induced Volatiles in Choice Behavior of an Omnivorous Predator}

\author{
Dionyssia A. Maselou ${ }^{1}$, Eirini Anastasaki ${ }^{2}$ and Panagiotis G. Milonas ${ }^{2 *}$ \\ ${ }^{1}$ Laboratory of Ecology and Environmental Sciences, Agricultural University of Athens, Athens, Greece, ${ }^{2}$ Biological Control \\ Laboratory, Department of Entomology and Agricultural Zoology, Benaki Phytopathological Institute, Kifissia, Greece
}

Macrolophus pygmaeus, Rambur (Heteroptera, Miridae) is a generalist predator found on various plant species and has also the ability to feed both on animal and plant tissue. Foraging behavior of $M$. pygmaeus and ultimately its efficacy as a biological control agent, is known to be affected by olfactory stimuli. Here, we elaborate on the response of this omnivore predator to volatiles produced by host plants by conducting olfactometric bioassays under laboratory conditions. In particular, we explored: (i) the relationship between previous experience and plant choice of $M$. pygmaeus nymphs by comparing its attractiveness to pepper and aubergine plants and (ii) how the presence of an aphid prey, Myzus persicae (Sulzer), or floral resources may influence choices made by $M$. pygmaeus. When the two host plants were provided, aubergine plants were found to be more attractive than pepper plants, regardless the previous experience of $M$. pygmaeus. Furthermore, the presence of $M$. persicae made aubergine plants more attractive to $M$. pygmaeus nymphs than uninfested aubergine plants. The gas chromatography-mass spectrometry analysis showed that plants infested with $M$. persicae emitted additional compounds as compared to the volatiles emitted from uninfested plants. In particular, four compounds, $(E)-\beta$-farnesene, $(E, E)$-TMTT, 2-methylbutanal oxime and dodecanal were found present only in the headspace of aubergine plants with aphids. However, M. pygmaeus did not show preference for the floral resources. Our results indicate that the response of $M$. pygmaeus is tuned toward the various stimuli in its habitat.

Keywords: Macrolophus pygmaeus, aubergine, pepper plant, Y-tube olfactometer, volatiles

\section{INTRODUCTION}

The generalist predator Macrolophus pygmaeus, Rambur (Hemiptera: Miridae), is a widely used biological control agent for several pests such as aphids, whiteflies, mites as well as the serious invasive pest Tuta absoluta (Meyrick) (Lepidoptera: Gelechiidae) on tomato crops (Perdikis et al., 2011; Calvo et al., 2012; Urbaneja et al., 2012; Zappala et al., 2013; Moreno-Ripoll et al., 2014). In particular, in Greece, M. pygmaeus is recorded to act as an efficient natural enemy (through natural colonization) in the control of aphids in field tomato crops (Lykouressis et al., 1999-2000). In addition, this mirid is also characterized for its omnivorous behavior, feeding on both plant and prey, which in some cases, depending on the suitability of the plant, allows development and 
reproduction in the absence of prey (Perdikis and Lykouressis, 1997, 1999, 2000). Unlike other omnivores, M. pygmaeus is considered as harmless and has been widely used in biological control programs (Castañé et al., 2011). However, Moerkens et al. (2016) reported that $M$. pygmaeus, can cause economic damage in tomato crops regardless the presence or absence of prey. In addition, Sanchez et al. (2018), reported that high populations of this mirid may lead to a yield reduction due to increased plant feeding. Yet, further research is necessary regarding other species of host plants. Recently, Zhang et al. (2018), have reported that M. pygmaeus can induce plant defenses in pepper plants. Similar results have been presented in previous studies concerning $M$. pygmaeus and other mirid species (Pappas et al., 2015, 2016; Pérez-Hedo et al., 2015a,b). In general, further consideration is required prior of using omnivores in biological control, since their ability to feed on both plant tissue and prey may have positive (survival of omnivores) and negative (preference for plant resources rather than prey) effects (Eubanks and Denno, 1999; Perdikis and Lykouressis, 1999; Maselou et al., 2014).

In order to switch between more than one trophic level, omnivores are equipped with morphological and physiological as well as phylogenetic and behavioral traits (Coll and Guershon, 2002). The behavioral characteristics for collection of information and action by a predator, has drawn a lot of attention by researchers in the recent years especially for predator species which can be used effectively in biological control (Ingegno et al., 2011, 2013, 2016; Lins et al., 2014; De Backer et al., 2015). Predator's orientation and the ability to detect and explore available patches with prey is related to various stimuli such as chemicals, visual and acoustic signals or even variation in temperature and humidity (Greany and Hagen, 1981; Letourneau, 1998).

It is well documented that olfactory stimuli are used by natural enemies for host or prey location and enhance efficacy by reducing searching time and increasing attack rates on prey (Dicke and Sabelis, 1988; Vet and Dicke, 1992; Dicke and Vet, 1999). These odors can derive from the prey or the host plant but can also be induced in plants in response to herbivore feeding (Greany and Hagen, 1981; Dicke et al., 1990; Vet and Dicke, 1992; Dicke and Vet, 1999; Hilker and Meiners, 2002). Environmental abiotic conditions and developmental stage of the plant are known to influence the blend of emitted volatiles (Boege and Marquis, 2005; Koricheva and Barton, 2012). The induction of volatiles are known to differ among herbivore species, or in the presence of more than one pests, but it has also been reported that different plant species infested by the same herbivorous species, emit different compounds of volatiles (Dicke and Sabelis, 1988; Turlings et al., 1990; Vet and Dicke, 1992; Tumlinson et al., 1993; Dicke, 1994, 1999; Sabelis et al., 1999; Bruce and Pickett, 2007; Ingegno et al., 2011; Cai et al., 2014). Moreover, plant feeding by omnivores may also affect the reproduction and development of herbivores through induced plant defenses (Pappas et al., 2015; Zhang et al., 2018).

Omnivores have been reported to utilize volatiles from host plants and herbivore-induced plant volatiles (HIPVs) to detect their host plant and prey (Lins et al., 2014; Rim et al., 2015, 2017). This response to HIPVs may be either inherited or acquired through experience (Vet and Dicke, 1992; Steidle and van Loon, 2003; de Boer and Dicke, 2006). Therefore, the effect of these volatiles to an omnivore's performance as biological control agent and their possible use as attractants, is of high importance during the implementation of a biological control strategy.

It has been reported that $M$. pygmaeus responds to volatiles from plants with prey, but not to volatiles emitted directly by the prey (Ingegno et al., 2011; Lins et al., 2014). Lins et al. (2014) found that $M$. pygmaeus exhibits a learning ability (experience) toward prey which may result in more efficient foraging. $M$. pygmaeus was able to discriminate a tomato plant infested by T. absoluta from a non-infested plant using olfactory cues (De Backer et al., 2015) as well as spider mite infested tomato plants over clean air (Pappas et al., 2018). However, little information is available regarding its response to volatiles produced from alternative plant food resources such as flowers. A previous study has shown that the presence of flowers on aubergine or pepper plants reduces $M$. pygmaeus predation on the aphid Myzus persicae, Sulzer (Heteroptera, Aphididae) (Maselou et al., 2014).

Based on the results of Maselou et al. (2014, 2015) and considering the importance of $M$. pygmaeus as a biological control agent and the rather limited knowledge of the role of volatiles stimuli to its behavior, we set out to elucidate the behavioral response of the predator toward plant resources using olfactometric bioassays. We specifically addressed the following hypotheses: (i) if plant choice in M. pygmaeus is influenced by previous experience, predators reared on plant species of different suitability (aubergine plants vs. pepper plants), would show different host plant selection behavior, (ii) the presence of alternative food resources (flower) or prey (aphid-infested plants) alter the volatile blend and considering that they are a feeding source for M. pygmaeus, their volatiles would be more attractive for the omnivore than the volatiles emitted from uninfested and non-flowering plants. We also assessed the predator preference for flowering plants vs. non-flowering plants with prey.

\section{MATERIALS AND METHODS}

\section{Plant Cultivation and Insect Rearing}

Aubergine (cv. Bonika F1) and pepper plants (cv. Vidi) were grown from March to October in a greenhouse in the Agricultural University of Athens at temperature $22.5 \pm 2.5^{\circ} \mathrm{C}$ (mean \pm $\mathrm{SD})$, under natural light. The plants used in all experiments were approximately of the same age, $20-25 \mathrm{~cm}$ tall with 56 true leaves. M. pygmaeus rearing was initiated by releasing adults and nymphs collected from a tomato field in central Greece (Co. Boeotia). The predators were reared separately on potted sweet pepper (cv. Vidi) and aubergine (cv. Bonika F1). Each week new non-flowering aubergine or pepper plants were provided to maintain the rearings. The two colonies of M. pygmaeus were maintained for at least 15 generations on each plant species provided ad libitum with Ephestia kuehniella Zeller (Lepidoptera: Pyralidae) eggs as a food supply. Eggs of the E. kuehniella were obtained from Koppert BV (Entofood, Berkel en Rodenrijs, The Netherlands). M. persicae rearing was established on aubergine plants by releasing adults and nymphs collected from aubergines in the premises of Agricultural 
University of Athens. All cultures were kept in wood-framed cages $(80 \mathrm{~cm}$ length $\times 80 \mathrm{~cm}$ width $\times 70 \mathrm{~cm}$ height $)$ in a greenhouse under the same conditions $\left(22.5 \pm 2.5^{\circ} \mathrm{C}\right.$, natural light).

\section{OLFACTOMETER BIOASSAYS}

The olfactory bioassays were conducted at $25 \pm 1^{\circ} \mathrm{C}, 65 \pm$ $5 \%$ RH under constant light. For each objective we tested the volatile sources presented in Table 1. In total eleven comparisons were carried out, six referring to our first objective, (effects of omnivore's experience on plant choice) and five to the response of $\mathrm{t}$ M. pygmaeus nymphs toward the presence of floral resources and prey. Responses of predator nymphs to volatiles were observed in a two-choice Y-tube glass olfactometer $(2.5 \mathrm{~cm}$ and $3.0 \mathrm{~cm}$ inside diameter at the entry and in the two side arms, respectively) formed by an entry arm (12 cm in length) and two side arms ( $15 \mathrm{~cm}$ in length, $70^{\circ}$ angle). The tube was positioned horizontally, and the two side arms were each connected to a glass container $(3.5 \mathrm{~L}$ or $0.5 \mathrm{~L}$ in volume for the assays with plants or individual flowers, respectively). The airflow was produced by an air pump adjusted at the end of the olfactometer with a flow meter to $250 \mathrm{~mL} \mathrm{~min}^{-1}$ and passed through an activated charcoal filter. The glass containers with volatile sources were kept behind a white panel, preventing insects from visually detecting the plants. When plants were used for the bioassays, pots were covered with aluminum foil to restrict the emission of volatiles from soil or plastic. All procedures were carried out wearing gloves. The flowers were cut just before the experiment and maintained in contact with water until use in the experiments. Fifth instar M. pygmaeus predators were used in the experiments after being deprived from prey for 24 hours to exclude the influence of variable hunger levels. These were obtained from nymphs of 1 st or 2nd instar that were transferred from the rearing cages to potted caged aubergine or pepper plants with eggs of E. kuehniella in a temperature controlled room in $25^{\circ} \mathrm{C}, 65 \pm 5 \% \mathrm{R}$. $\mathrm{H}$. and a photoperiod of $16: 8$ (L:D) $\mathrm{h}$ and left to develop to the 5 th instar. Approximately $1 \mathrm{~h}$ before trials were initiated, the predators were placed into individual tubes. Each nymph was individually introduced at the downwind end of the entry arm and observed until covering more than $10 \mathrm{~cm}$ inside each chosen arm. The experiments took place from 12:00 p.m. to 17:00 p.m. since $M$. pygmaeus has been previously reported to be more active during the afternoon (Perdikis et al., 2004). Nymphs not making a choice for a side arm within 10 min were considered as having made no choice and were excluded from data analysis. Each predator was tested only once and then discarded. The final number of $M$. pygmaeus nymphs that had made a choice for each pair of volatiles was 40. After testing a batch of five nymphs, the volatile sources were switched between left and right sides of the arms to minimize positional bias. After testing ten nymphs, the Y-tube and glass containers were washed with neutral soap and alcohol $(70 \%)$ and autoclaved at $120^{\circ} \mathrm{C}$ for 20 min. Approximately, 8-10 insects were tested daily and plants or flowers were replaced daily, therefore 5-6 plants or 10-15 flowers were used per treatment.

\section{Headspace Collection and Analysis of Plant Volatiles}

Volatile collection was performed from uninfested, flowering and aphid infested aubergine plants as described by Anastasaki et al. (2018) with slight modifications. A glass container (3.5 L) as described above was used for volatile collection. Singlepotted plants were placed in each glass container, with pot and soil wrapped with aluminum foil. Purified air, through an activated charcoal filter, passed through the glass containers. Plant volatiles were drawn by vacuum pump (Dymax 5, Charles Austen Pumps Ltd, UK) with a rate of $360 \mathrm{~mL} / \mathrm{min}$ onto a Teflon made trap $(5 \mathrm{~cm}$ length $\times 3 \mathrm{~mm}$ id) containing $30 \mathrm{mg}$ Porapak Q (80/100 mesh, Supelco, Bellefonte, USA) tapped with a $2 \mathrm{~mm}$ glass wool and $3 \mathrm{~mm}$ Teflon tubes in each end. Prior to the analysis, traps were sequentially washed with $1 \mathrm{~mL}$ methanol, diethyl ether, and n-pentane (Fisher Chemicals, Bishop, UK) and blown dry with $\mathrm{N}_{2}$. Collection of headspace volatiles was performed continuously for $6 \mathrm{~h}$. Three replicates per treatment were carried out. The collection of volatiles was carried out at the same experimental conditions and time period as for the olfactometer bioassays (12:00-18:00). After volatile collection,

TABLE 1 | Olfactometer bioassays involving M. pygmaeus nymphs originating either from pepper or aubergine plants (see details in the Materials and Methods).

\begin{tabular}{|c|c|c|c|c|}
\hline Objective & $\begin{array}{l}\text { M. pygmaeus host } \\
\text { plant origin }\end{array}$ & Odor source 1 & & Odor source 2 \\
\hline \multirow[t]{6}{*}{1} & Pepper & Pepper plant & VS. & Air \\
\hline & & Aubergine plant & VS. & Air \\
\hline & & Pepper plant & VS. & Aubergine plant \\
\hline & Aubergine & Aubergine plant & VS. & Air \\
\hline & & Pepper plant & VS. & Air \\
\hline & & Pubergine plant & vs. & Pepper plant \\
\hline \multirow[t]{5}{*}{$\|$} & Pepper & Flower from pepper plant & vS. & Air \\
\hline & Aubergine & Flower from aubergine plant & VS. & Air \\
\hline & Aubergine & Aphid-infested aubergine plant & VS. & Uninfested aubergine plant \\
\hline & & Flowering aubergine plant & vs. & Uninfested aubergine plant \\
\hline & & Flowering aubergine plant & VS. & Aphid-infested aubergine plant \\
\hline
\end{tabular}


traps were extracted immediately with $0.5 \mathrm{~mL}$ n-pentane. Sample volumes were reduced to $150 \mu \mathrm{L}$ and stored in a freezer (at $-20^{\circ} \mathrm{C}$ ) in a sealed GC vial with conical inserter until use.

The identification of the chemical compounds was performed with gas chromatography-mass spectrometry (GC-MS). One microliter of the extract was injected in a Varian CP-3800 GC, with a 1079 injector coupled with a 1200L quadrupole mass spectrometer. Separation of the analytes was performed with a Varian VF5ms capillary column $(30 \mathrm{~m}, 0.25 \mathrm{~mm}$ i.d, $0.25 \mu \mathrm{m}$ film thickness). Splitless mode was set to $0.75 \mathrm{~min}$. Then, the injector split ratio was set at $80: 1$. At $5 \mathrm{~min}$, the split ratio was set to $70: 1$. The flow rate of the carrier gas helium was
$1 \mathrm{~mL} \min ^{-1}$. The column temperature was maintained at $40^{\circ} \mathrm{C}$ for $1 \mathrm{~min}$, increased with a rate of $1.2^{\circ} \mathrm{C} \mathrm{min}^{-1}$ to $65^{\circ} \mathrm{C}$ and with a rate at $3^{\circ} \mathrm{C} \mathrm{min}^{-1}$ to $180^{\circ} \mathrm{C}$. The column was heated with a rate of $15^{\circ} \mathrm{C} \mathrm{min}^{-1}$ to the final temperature of $250^{\circ} \mathrm{C}$. Mass spectrometer was operated in Electron ionization mode (EI) with ion energy of $-70 \mathrm{eV}$, filament current $50 \mu \mathrm{A}$ and source temperature $200^{\circ} \mathrm{C}$. Data acquisition was performed in full scan (MS) with scanning range 40-300 amu. Compounds were identified by comparing their retention time and mass spectra with that of commercial standards whenever possible or tentatively by comparing their elution order, mass spectra and RI values from Adams (2007); NIST, 2005; Wiley 275 mass spectra libraries and literature data (Adams, 2007; Anastasaki

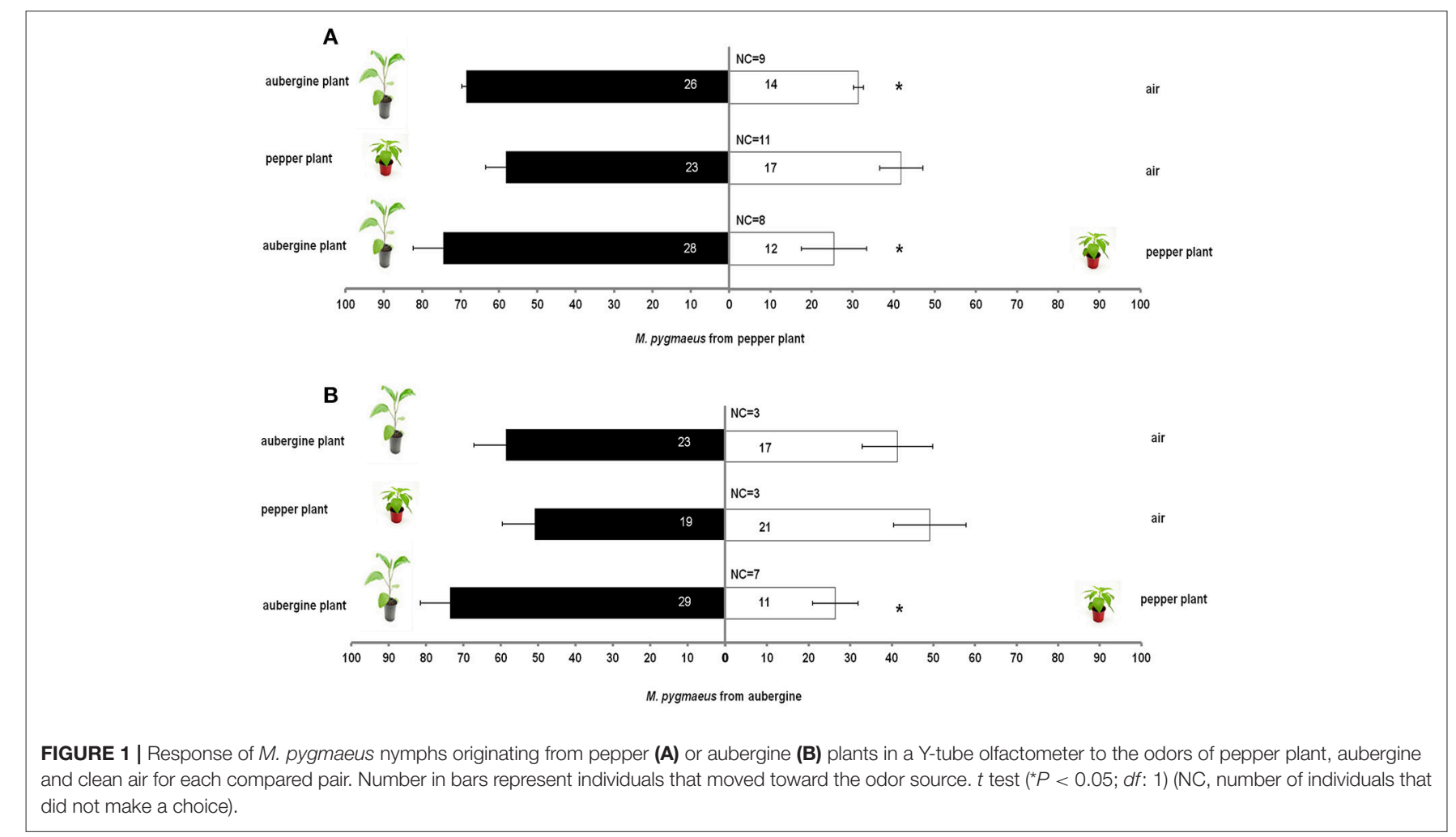

A

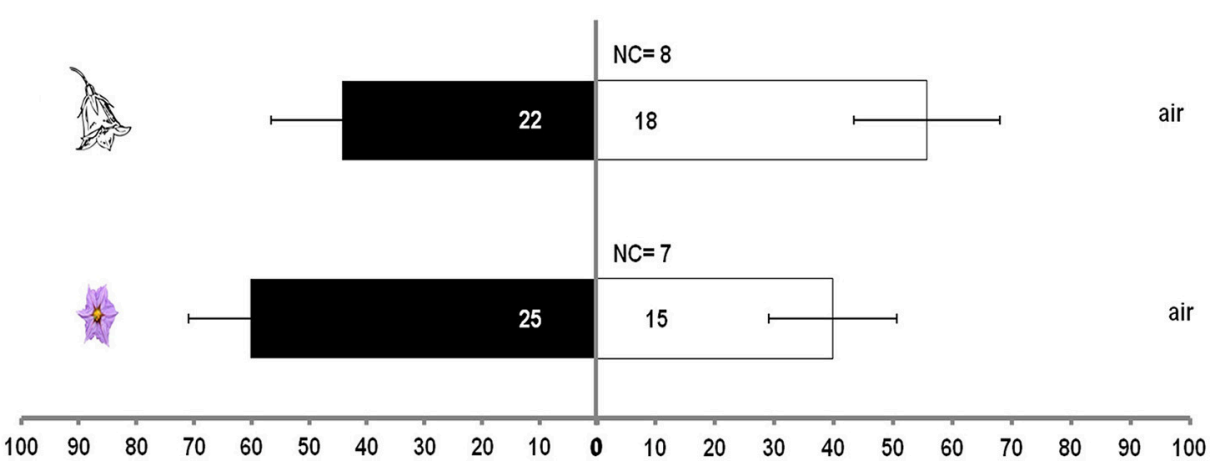

FIGURE 2 | Response of M. pygmaeus nymphs originating from pepper or aubergine plants in a Y-tube olfactometer to the odors of one pepper flower or one aubergine flower over clean air. Numbers in bars represent individuals that moved toward the odor source. $t$ test $(P<0.05 ; d f: 1)$ (NC, number of individuals that did not make a choice). (A) Flower from pepper plant. (B) Flower from aubergine plant. 


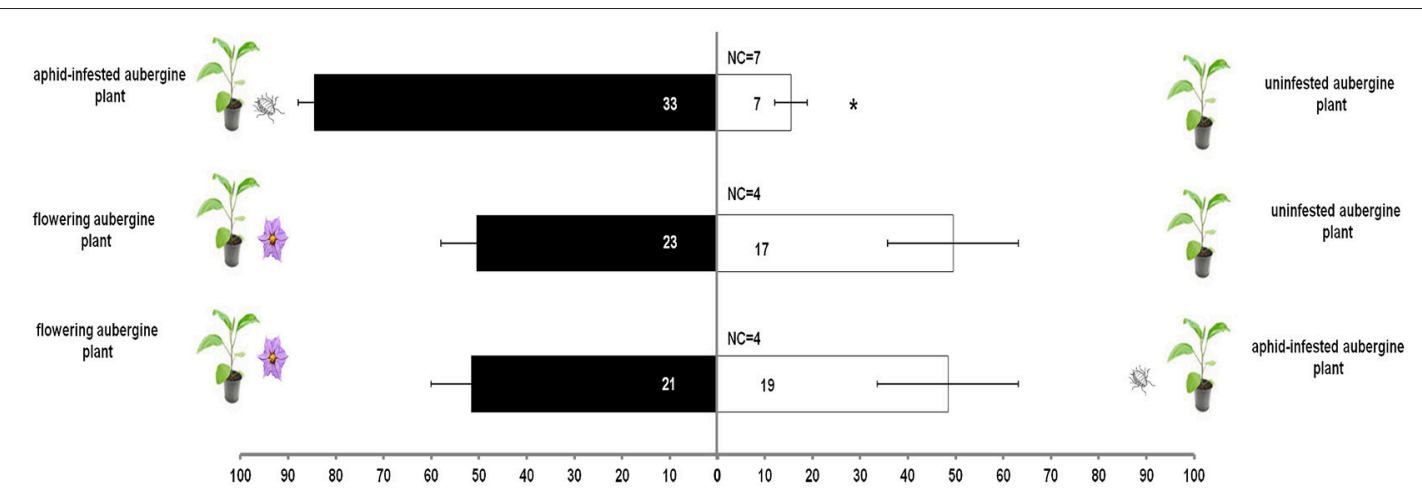

FIGURE 3 | Response of M. pygmaeus nymphs originating from aubergine plants in a Y-tube olfactometer to the odors of an aphid-infested aubergine over an uninfested aubergine, a flowering aubergine over an uninfested aubergine and a flowering aubergine over an aphid-infested aubergine plant. Number in bars represents individuals that moved toward the odor source. $t$ test ( ${ }^{*} P<0.05$; df: 1) (NC, number of individuals that did not make a choice).

et al., 2018). We also used retention indices (RI) of a series of n-alkane $\left(\mathrm{C}_{8}-\mathrm{C}_{20}\right)$.

\section{Statistical Analysis}

In the olfactometer bioassays, the responses of $M$. pygmaeus nymphs were analyzed by a logistic regression to investigate the influence of predator host plant origin. Each bioassay with one pair of plants (or plant vs. air) served as a replicate. Predator host plant origin and plant treatment (pepper or aubergine) were used as fixed factors. Non-significant interactions were removed from the final model (Agresti, 2013). In comparisons of plants vs. air the number of M. pygmaeus choosing plants (aubergine or pepper) out of the total individuals responding was used as the response variable. In comparison of aubergine plants vs. pepper plants, the number of individuals choosing aubergine plants out of total individuals responding was used as the response variable. Logistic regression was also used to investigate the influence of flowers on $M$. pygmaeus behavioral choices. In this case, the number of individuals moving toward the flower odor chamber out of total responding was the response variable. The effect of plant treatment (i.e., flowering plant or aphid infested plant) was analyzed by logistic regression and the number of individuals choosing flowering or aphid infested plants out of total responding was used as the response variable. To determine whether there was a preference for an odor source within a treatment combination, we used one sample $t$-test on the proportion of $M$. pygmaeus preferring the response variable in each replicate. Data were arcsine-transformed and tested against arcsine (0.5), i.e., no preference for either odor source. Nymphs that did not make a choice were excluded from the statistical analysis. All analyses were performed using SPSS version 19.0 (SPSS, Chicago, IL) ${ }^{1}$.

The total ion chromatogram peak areas of identified compounds were calculated by Varian MS Workstation software (version 6.9). The effect of treatment on the relative peak area of each volatile identified was determined with analysis of variance

$\overline{{ }^{1} \text { SPSS v. 19.0.0., 2010. SPSS Inc., Chicago }}$ and comparisons among means were performed using the LSD test. Volatile data were also log-transformed and subjected to multivariate analysis with SIMCA 14.1 software (Umetrics, Umeå, Sweden). Specifically, projections to latent structuresdiscriminant analysis (PLS-DA) were performed with Pareto scaling.

\section{RESULTS}

\section{Olfactometer Bioassays}

Host plant origin (aubergine or pepper) of M. pygmaeus nymphs had a significant effect on the response of nymphs toward aubergine or pepper plants in comparison with air $\left(\chi^{2}=34.9, d f=15, P=0.002\right)$. When $M$. pygmaeus originated from pepper plants, the nymphs were attracted to aubergine plants in comparison with air $(t=14.4$, $d f=4, P<0.001)$. No other significant differences were observed between aubergine or pepper plants in comparison with air (Pepper plant vs. clean air $t_{\text {pepper }}=1.6, d f=4$, $P=0.185 ; t_{\text {aubergine }}=0.2, d f=4, P=0.835$; Aubergine plant vs. clean air: $t_{\text {aubergine }}=1.1, d f=4, P=0.332$, Figure 1).

There was no significant effect of $M$. pygmaeus nymph origin in comparisons of aubergines over pepper plants $\left(\chi^{2}=11.1\right.$, $d f=8, P=0.197)$. M. pygmaeus nymphs were more attracted to aubergine than to pepper plants $\left(t_{\text {pepper }}=2.55, d f=5, P=0.05\right.$; $t_{\text {aubergine }}=4.03, d f=5, P=0.01$, Figure 1).

Treatment had no significant effect in the case of single aubergine or pepper flower over clean air $\left(\chi^{2}=13.8, d f=8\right.$, $P=0.08)$. M. pygmaeus nymphs did not discriminate between clean air and volatiles from an aubergine $(t=1.1, d f=4$, $P=0.337)$ or a pepper flower $(t=0.36, d f=4, P=0.738)$ (Figure 2).

M. pygmaeus nymphs did not discriminate between flowering and unifensted or aphid-infested aubergine plants $\left(\chi^{2}=26.4\right.$, $d f=18, P=0.092$, Figure 3). Predator nymphs were more attracted to aphid-infested aubergine plants than to uninfested ones ( $t=7.9, d f=3, P=0.004$, Figure 3 ). 
TABLE 2 | Volatile composition of headspace of uninfested (CON), flowering (FLO), and aphid infested aubergine plants (APH) expressed as total peak area (102 \pm $\mathrm{SE}, n=3)$.

\begin{tabular}{|c|c|c|c|c|c|c|c|}
\hline ID & $\mathbf{R} \mathbf{I}^{\mathbf{a}}$ & Compounds & CON & FLO & APH & $F^{b}$ & $P^{\mathrm{c}}$ \\
\hline 1 & 800 & Octane & $3.08 \pm 1.02 a^{d}$ & $0.00 \mathrm{~b}$ & $3.48 \pm 1.28 a$ & 14.48 & $0.005^{\star}$ \\
\hline 2 & 802 & Hexanal & $0.00 b$ & $3.85 \pm 0.92 a$ & $0.00 b$ & 17.77 & $0.003^{\star}$ \\
\hline 3 & 811 & Butyl acetate & $0.00 \mathrm{~b}$ & $0.06 \pm 0.04 b$ & $0.61 \pm 0.16 a$ & 13.08 & $0.006^{\star}$ \\
\hline 4 & 835 & 2-methylbutanal oxime & $0.00 \mathrm{~b}$ & $0.00 b$ & $1.00 \pm 0.45 a$ & 4.92 & $0.054^{\star}$ \\
\hline 5 & 856 & m-xylene & $4.39 \pm 1.52 a$ & $0.00 \mathrm{~b}$ & $4.29 \pm 1.55 \mathrm{ab}$ & 4.00 & 0.079 \\
\hline 6 & 864 & o-xylene & $3.91 \pm 0.42 a$ & $6.02 \pm 1.87 \mathrm{a}$ & $8.29 \pm 1.47 a$ & 2.47 & 0.165 \\
\hline 7 & 887 & p-xylene & $1.79 \pm 0.21 a$ & $2.42 \pm 0.11 \mathrm{a}$ & $3.54 \pm 1.15 a$ & 1.71 & 0.259 \\
\hline 8 & 900 & Nonane & $1.04 \pm 0.15 b$ & $2.92 \pm 0.79 a$ & $0.84 \pm 0.19 b$ & 5.79 & $0.040^{\star}$ \\
\hline 9 & 906 & Heptanal & $0.26 \pm 0.26 b$ & $0.76 \pm 0.16 a b$ & $1.87 \pm 0.75 a$ & 3.22 & 0.112 \\
\hline 10 & 927 & $\alpha$-pinene & $5.02 \pm 0.29 a$ & $5.28 \pm 0.01 a$ & $3.99 \pm 0.88 a$ & 1.62 & 0.273 \\
\hline 11 & 938 & $\beta$-citronellene & $0.00 b$ & $3.78 \pm 0.95 a$ & $0.00 b$ & 15.90 & $0.004^{\star}$ \\
\hline 12 & 978 & m-menth-1-ene & $1.60 \pm 0.23 a$ & $1.90 \pm 0.17 a$ & $0.84 \pm 0.16 b$ & 8.47 & $0.018^{\star}$ \\
\hline 13 & 972 & $\beta$-pinene & $1.33 \pm 0.27 a$ & $1.02 \pm 0.08 a$ & $2.02 \pm 0.47 a$ & 2.58 & 0.156 \\
\hline 14 & 976 & p-menthane & $1.15 \pm 0.46 a$ & $1.75 \pm 0.48 a$ & $1.27 \pm 0.66 a$ & 0.34 & 0.726 \\
\hline 15 & 985 & Hydrocarbon 1 & $3.81 \pm 1.12 \mathrm{a}$ & $3.90 \pm 0.19 a$ & $5.17 \pm 1.10 \mathrm{a}$ & 0.69 & 0.540 \\
\hline 16 & 993 & Butyl butanoate & $0.97 \pm 0.35 a b$ & $0.00 \mathrm{~b}$ & $1.81 \pm 0.28 a$ & 8.31 & $0.026^{\star}$ \\
\hline 17 & 1000 & Decane & $7.89 \pm 1.34 a$ & $7.78 \pm 2.23 a$ & $1.59 \pm 0.61 b$ & 5.45 & $0.045^{\star}$ \\
\hline 18 & 1005 & 3- $\delta$-carene & $3.81 \pm 0.65 a$ & $2.54 \pm 0.29 a$ & $3.06 \pm 0.25 a$ & 2.13 & 0.201 \\
\hline 19 & 1016 & Hydrocarbon 2 & $3.91 \pm 0.88 a$ & $1.35 \pm 0.78 a$ & $1.67 \pm 0.96 a$ & 2.55 & 0.158 \\
\hline 20 & 1021 & p-cymene & $1.54 \pm 0.42 a$ & $0.56 \pm 0.32 a$ & $1.20 \pm 0.07 a$ & 2.62 & 0.152 \\
\hline 21 & 1025 & Limonene & $3.89 \pm 0.21 a$ & $4.54 \pm 0.23 a$ & $6.16 \pm 1.20 \mathrm{a}$ & 2.63 & 0.152 \\
\hline 22 & 1028 & Eucalyptol & $1.12 \pm 0.27 b$ & $2.29 \pm 0.08 a$ & $0.56 \pm 0.14 b$ & 23.76 & $0.001^{\star}$ \\
\hline 23 & 1030 & Ethylhexanol & $3.40 \pm 1.25 a$ & $2.53 \pm 0.01 a$ & $3.08 \pm 0.60 a$ & 0.30 & 0.753 \\
\hline 24 & 1032 & Benzyl alcohol & $0.13 \pm 0.13 a$ & $0.00 a$ & $0.00 a$ & 1.00 & 0.422 \\
\hline 25 & 1034 & Unknown 1 & $0.36 \pm 0.14 a$ & $0.43 \pm 0.25 a$ & $0.00 \mathrm{a}$ & 1.95 & 0.222 \\
\hline 26 & 1044 & Hydrocarbon 3 & $0.54 \pm 0.26 a$ & $0.62 \pm 0.21 a$ & $0.69 \pm 0.53 a$ & 0.05 & 0.956 \\
\hline 27 & 1055 & Hydrocarbon 4 & $1.87 \pm 0.51 a$ & $1.52 \pm 0.59 a$ & $0.38 \pm 0.31 a$ & 2.59 & 0.155 \\
\hline 28 & 1061 & Hydrocarbon 5 & $1.82 \pm 0.23 a$ & $1.38 \pm 0.35 a$ & $1.17 \pm 0.15 a$ & 1.69 & 0.262 \\
\hline 29 & 1063 & Hydrocarbon 6 & $1.23 \pm 0.49 a$ & $0.99 \pm 0.24 a b$ & $0.00 \mathrm{~b}$ & 4.35 & 0.068 \\
\hline 30 & 1076 & Dihydromyrcenol & $2.78 \pm 0.14 a$ & $3.44 \pm 0.67 a$ & $2.30 \pm 0.33 a$ & 1.73 & 0.255 \\
\hline 31 & 1100 & Undecane & $5.90 \pm 0.52 a$ & $0.31 \pm 0.12 b$ & $1.21 \pm 0.35 b$ & 66.89 & $0.000^{\star}$ \\
\hline 32 & 1101 & Linalool & $0.90 \pm 0.19 b$ & $4.81 \pm 0.32 a$ & $3.03 \pm 0.97 a$ & 10.76 & $0.010^{\star}$ \\
\hline 33 & 1109 & Nonanal & $5.11 \pm 0.46 a$ & $3.72 \pm 0.53 a$ & $5.30 \pm 0.41 a$ & 3.16 & 0.116 \\
\hline 34 & 1114 & (E)4,8-dimethyl-1,3,7-nonatriene & $0.14 \pm 0.03 b$ & $0.21 \pm 0.03 b$ & $0.61 \pm 0.12 a$ & 16.69 & $0.004^{\star}$ \\
\hline 35 & 1115 & Hydrocarbon 7 & $0.43 \pm 0.01 a$ & $0.42 \pm 0.07 a$ & $0.17 \pm 0.01 b$ & 11.20 & $0.009^{\star}$ \\
\hline 36 & 1146 & Camphor & $0.69 \pm 0.19 a$ & $1.38 \pm 0.38 a$ & $0.89 \pm 0.22 a$ & 1.65 & 0.269 \\
\hline 37 & 1148 & Menthone & $0.44 \pm 0.07 a b$ & $0.76 \pm 0.09 a$ & $0.25 \pm 0.13 b$ & 6.62 & $0.030^{\star}$ \\
\hline 38 & 1165 & 2-(Z)-nonenal & $0.83 \pm 0.15 a$ & $0.63 \pm 0.15 a$ & $0.66 \pm 0.06 a$ & 0.75 & 0.511 \\
\hline 39 & 1166 & Benzyl acetate & $0.54 \pm 0.27 a$ & $0.80 \pm 0.17 a$ & $0.79 \pm 0.17 a$ & 0.49 & 0.638 \\
\hline 40 & 1168 & Isoborneol & $0.00 b$ & $0.45 \pm 0.07 a$ & $0.36 \pm 0.06 a$ & 18.89 & $0.003^{\star}$ \\
\hline 41 & 1191 & Phenyl ethyl acetate & $0.29 \pm 0.08 a$ & $0.53 \pm 0.11 \mathrm{a}$ & $0.52 \pm 0.02 a$ & 2.88 & 0.133 \\
\hline 42 & 1194 & $\alpha$-terpineol & $0.56 \pm 0.09 a$ & $0.64 \pm 0.15 a$ & $0.66 \pm 0.04 a$ & 0.28 & 0.769 \\
\hline 43 & 1200 & Dodecane & $1.83 \pm 0.12 \mathrm{a}$ & $2.43 \pm 0.06 a$ & $1.97 \pm 0.33 a$ & 2.32 & 0.180 \\
\hline 44 & 1204 & Verbenone & $0.13 \pm 0.04 a$ & $0.11 \pm 0.07 a$ & $0.19 \pm 0.10 a$ & 0.32 & 0.737 \\
\hline 45 & 1207 & Decanal & $3.05 \pm 0.19 a$ & $2.61 \pm 0.51 a$ & $3.00 \pm 0.45 a$ & 0.31 & 0.748 \\
\hline 46 & 1232 & Citronellol & $0.00 b$ & $0.23 \pm 0.03 a$ & $0.22 \pm 0.07 a$ & 8.63 & $0.017^{\star}$ \\
\hline 47 & 1253 & Linalyl acetate & $0.36 \pm 0.08 a$ & $0.57 \pm 0.01 a$ & $0.41 \pm 0.15 a$ & 1.37 & 0.323 \\
\hline 48 & 1274 & Unknown 2 & $0.56 \pm 0.17 a$ & $0.00 \mathrm{a}$ & $0.55 \pm 0.26 a$ & 3.19 & 0.114 \\
\hline 49 & 1281 & Unknown 3 & $0.14 \pm 0.07 a$ & $0.38 \pm 0.22 a$ & $0.21 \pm 0.08 a$ & 0.76 & 0.510 \\
\hline 50 & 1286 & Isobornyl acetate & $0.57 \pm 0.13 a$ & $1.01 \pm 0.07 a$ & $0.58 \pm 0.22 a$ & 2.65 & 0.150 \\
\hline
\end{tabular}


TABLE 2 | Continued

\begin{tabular}{|c|c|c|c|c|c|c|c|}
\hline ID & $\mathbf{R} \mathbf{I}^{\mathbf{a}}$ & Compounds & CON & FLO & APH & $F^{b}$ & $P^{\mathrm{c}}$ \\
\hline 51 & 1300 & Tridecane & $0.83 \pm 0.16 a$ & $0.84 \pm 0.07 a$ & $1.02 \pm 0.20 a$ & 0.48 & 0.639 \\
\hline 52 & 1311 & Undecanal & $0.33 \pm 0.07 a$ & $0.30 \pm 0.01 a$ & $0.27 \pm 0.05 a$ & 0.32 & 0.736 \\
\hline 53 & 1322 & Hydrocarbon 8 & $1.02 \pm 0.53 a$ & $0.55 \pm 0.32 a$ & $0.55 \pm 0.36 a$ & 0.44 & 0.662 \\
\hline 54 & 1344 & Unknown 4 & $0.83 \pm 0.15 a$ & $0.00 \mathrm{a}$ & $0.82 \pm 0.82 a$ & 0.61 & 0.578 \\
\hline 55 & 1371 & Unknown 5 & $3.88 \pm 0.37 b$ & $5.52 \pm 0.17 a$ & $3.25 \pm 0.60 b$ & 7.73 & $0.022^{\star}$ \\
\hline 56 & 1400 & Tetradecane & $1.39 \pm 0.32 a$ & $1.30 \pm 0.01 a$ & $2.07 \pm 0.69 a$ & 0.93 & 0.444 \\
\hline 57 & 1405 & Longifolene & $0.30 \pm 0.05 a$ & $0.31 \pm 0.03 a$ & $0.32 \pm 0.06 a$ & 0.02 & 0.977 \\
\hline 58 & 1412 & Dodecanal & $0.00 \mathrm{a}$ & $0.00 a$ & $0.16 \pm 0.08 a$ & 4.00 & 0.079 \\
\hline 59 & 1431 & (Z)- $\alpha$-bermamotene & $0.38 \pm 0.4 b$ & $0.52 \pm 0.10 b$ & $1.79 \pm 0.06 a$ & 54.87 & $0.000^{\star}$ \\
\hline 60 & 1452 & Geranyl acetone & $0.83 \pm 0.29 a$ & $0.73 \pm 0.30 a$ & $0.00 \mathrm{a}$ & 3.53 & 0.097 \\
\hline 61 & 1453 & $(E)$ - $\beta$-farnesene & $0.00 \mathrm{~b}$ & $0.00 b$ & $1.23 \pm 0.10 a$ & 15.79 & $0.004^{\star}$ \\
\hline 62 & 1500 & Pentadecane & $1.00 \pm 0.30 a$ & $0.91 \pm 0.11 a$ & $1.35 \pm 0.60 a$ & 0.36 & 0.709 \\
\hline 63 & 1523 & Lilal & $0.43 \pm 0.08 a$ & $0.37 \pm 0.06 a$ & $0.35 \pm 0.18 a$ & 0.14 & 0.869 \\
\hline 64 & 1529 & Unknown 6 & $0.80 \pm 0.31 a$ & $0.44 \pm 0.26 a$ & $0.46 \pm 0.18 a$ & 0.64 & 0.558 \\
\hline 65 & 1570 & Unknown 7 & $0.25 \pm 0.07 a$ & $0.90 \pm 0.52 a$ & $0.00 a$ & 2.361 & 0.175 \\
\hline 66 & 1575 & $\begin{array}{l}(E . E)-4,8,12 \text {-trimethyl-1,3,7,11- } \\
\text { tridecatetraene }\end{array}$ & $0.00 a$ & $0.00 a$ & $0.20 \pm 0.05 b$ & 15.79 & 0.004 \\
\hline 67 & 1583 & Unknown 8 & $1.68 \pm 0.09 b$ & $0.84 \pm 0.26 c$ & $3.34 \pm 0.29 a$ & 29.92 & $0.001^{\star}$ \\
\hline 68 & 1600 & Hexadecane & $0.91 \pm 0.22 a$ & $0.82 \pm 0.09 a$ & $0.54 \pm 0.16 a$ & 1.62 & 0.274 \\
\hline
\end{tabular}

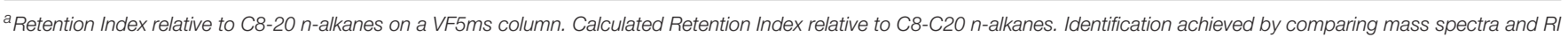
with authentic standard (s) or tentative ( $t$ ) with mass spectra libraries and literature data (Adams, 2007; Anastasaki et al., 2018).

${ }^{b} \mathrm{~F}$ values, $d f=2$.

${ }^{c}$ Probability values for each F-test. Significant values $(P<0.05)$ are denoted in bold and marked with an asterisk for each compound

${ }^{d}$ Mean values followed by different letters are significantly different $(P<0.05)$.

\section{Headspace Collection and Analysis of Plant Volatiles}

In total 68 compounds were isolated from the headspace of aubergine plants (Table 2). Among them, 49 were found in all three plant categories. We confirmed that differences exist in volatile emissions of uninfested, flowering and aphid-infested plants. Dodecanal, $(E)$ - $\beta$-farnesene, 2-methylbutanal oxime and $(E, E)-4,8,12$-trimethyl-1,3,7,11-tridecatetraene $\quad-[(E, E)$ TMTT] were found only in the volatile blend of aphid-infested aubergines. Furthermore, hexanal and $\beta$-citronellene were found only in the headspace of flowering aubergines, while benzyl alchool was isolated only in the headspace of non-infested ones. Additionally, unknown compounds 1 and 7 , hydrocarbon 6 and geranyl acetone were emitted from uninfested and flowering aubergines but not from aphid-infested plants. Terpenoids, including monoterpenes and sesquiterpenes, was the most abundant class of compounds. The main monoterpenes identified on all plant treatments were $\alpha$ - and $\beta$-pinene, limonene and $3-\delta$-carene. Significant emissions of esters, aromatic hydrocarbons and hydrocarbons $\left(F_{\text {est }}=14.260, d f=2\right.$, $P=0.005 ; F_{\text {ahyd }}=6.940, d f=2, P=0.027 ; F_{\text {hyd }}=46.538$, $d f=2, P<0.001)$ were observed in the volatile blend of all plants. The total relative peak area of terpenoids aldehydes and alchools did not differ significantly between treatments $\left(F_{\text {terp }}=1.752, d f=2, P=0.252 ; F_{\text {ald }}=1.741, d f=2\right.$, $P=0.253 ; F_{\text {alc }}=1.919, d f=2, P=0.227$ ) (Figure 4). Plants infested with $M$. persicae had significantly higher emissions of butyl acetate, 2-methylbutanal oxime, heptanal, (E)-4, 8-dimethyl-1,3,7-nonatriene [(E)-DMNT], citronellol, $(Z)-\alpha$ bermamotene, $(E)$ - $\beta$-farnesene, $(E, E)$-TMTT and unknown 8 compared to uninfested plants (Table 2).

Projection to latent structures discriminant analysis (PLSDA) of all treatments together presented three major clusters of samples, where the aphid-infested and the flowering plants were separated from the uninfested aubergine plants and from each other (Figure 5A). The PLS-DA analysis identified 24 compounds with a VIP value higher than 1 (Table 3). Figure 5B shows the contribution of emitted volatile compounds to the two principal components, which explained 36.3 and $23.3 \%$ of the variance, respectively.

\section{DISCUSSION}

In the present study, the response of $M$. pygmaeus nymphs toward plant resources was evaluated. Our first hypothesis that predator's plant experience affects the preference of nymphs was partly supported by our findings. Aubergine plants were more attractive to $M$. pygmaeus nymphs over air originating from pepper plants. However, our olfactory trials revealed that regardless the host plant origin of the predator pepper or aubergine plants), M. pygmaeus was more attracted to aubergine than to pepper plants. Previous studies have focused on adult behavior. Ingegno et al. (2011) have studied the effect of different host plants species in comparison with tomato plants on the response of $M$. pygmaeus adults. However, the influence of rearing plant on the choice behavior of M. pygmaeus nymphs has 


\section{Main indentified compounds}

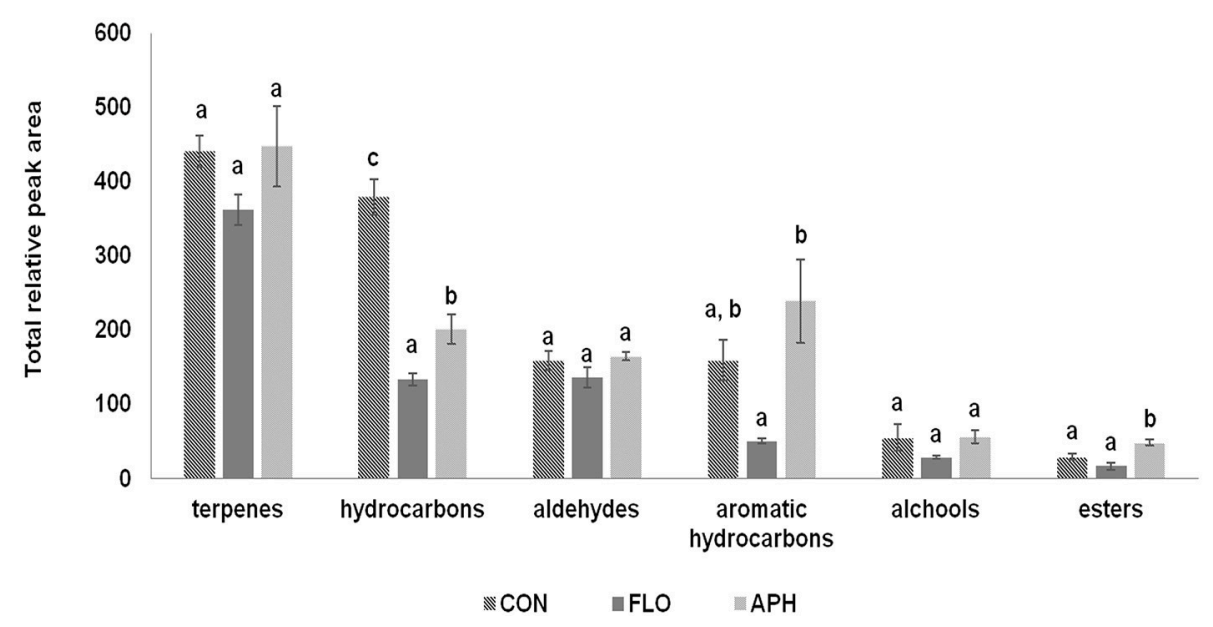

FIGURE 4 | Volatile composition of aubergine plants expressed as total peak area ( $\pm \mathrm{SE}, n=3$ ) according to volatile chemical classes emitted by uninfested (CON), flowering (FLO) and aphid-infested aubergine plants. Treatments followed by a different letter are significantly different (ANOVA, $P<0.05$ ).
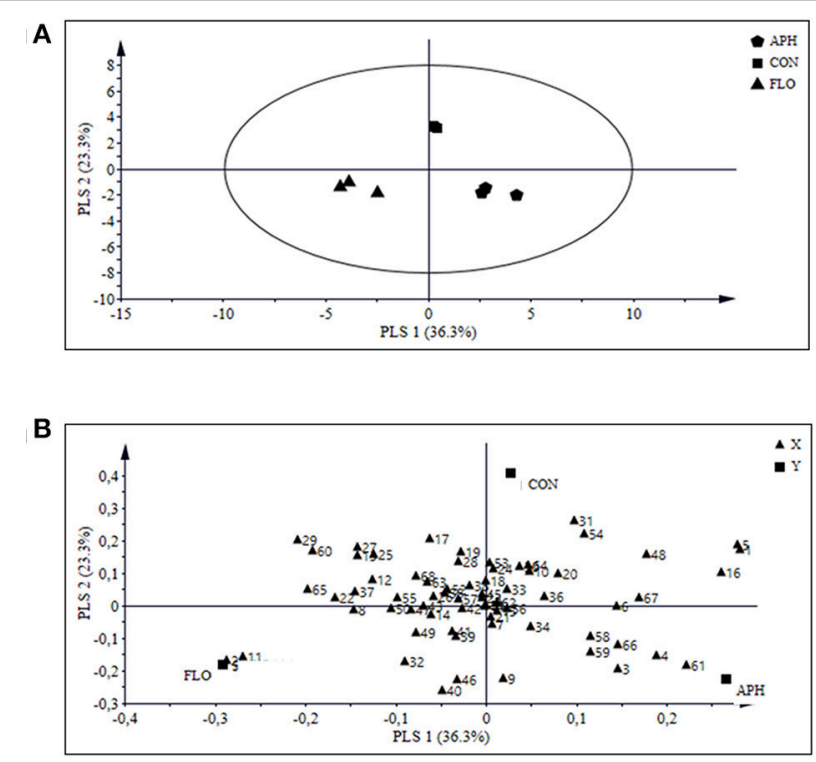

FIGURE 5 | Projection to Latent Structures Discriminant Analysis (PLS-DA) of volatile compounds produced by aphid-infested aubergine plants $(n=3$, APH), flowering aubergine plants $(n=3$, FLO) or uninfested plants $(n=3$, $\mathrm{CON}$ ). The score plot (A) visualizes the structure of the samples according to the first two PLS components with explained variance in brackets. The ellipse defines Hotelling's $T^{2}$ confidence region (95\%). The loading plot (B) defines the orientation of the PLS panels with the original variables in the $\mathrm{X}$ (volatile variables) and $Y$ space (class variables: APH, FLO, and CON). For number interpretation of the volatiles please refer to Table 2.

not been studied previously. In the present study we tested two host-plant species, pepper and aubergine plants, which according to Perdikis and Lykouressis $(2000,2004 a, b)$ have shown different suitability for the development and survival of M. pygmaeus and have been characterized among a wide range of host plants as the least and most suitable plant, respectively. Other mirid species, such as Dicyphus hesperus Knight (Hemiptera:Miridae), both adults and nymphs, exhibit a similar behavior by choosing host plants on which nymph survival without prey was substantial (Sanchez et al., 2004).

Our second hypothesis that the volatiles emitted by a flower or prey would affect the response of $M$. pygmaeus nymphs was supported in the case of prey only. Predator nymphs were attracted to aphid-infested aubergines over uninfested ones. Previous studies have shown that M. pygmaeus adults do not respond in the presence of prey without the plant (Ingegno et al., 2011; Lins et al., 2014). Following the outcomes of Maselou et al. (2014), we carried out olfactometer bioassays in a plant scale using aubergine plants since they were found to be more attractive to $M$. pygmaeus nymphs. Likewise, there was a tendency for attraction toward flowering aubergine over nonflowering plants though not statistically significant. Given that M. pygmaeus nymphs can also feed on plant pollen (Perdikis and Lykouressis, 2000; Vandekerkhove and De Clercq, 2010), we expected that flowering plants would be more attractive than non-flowering plants. The fact that $M$. pygmaeus nymphs did not show a clear preference for the flowering plants suggests that these floral resources may be exploited after the establishment of the species on the plant. On the contrary, M. pygmaeus nymphs showed a clear preference for aphid-infested over uninfested aubergine plants. Similar outcomes on adults of M. pygmaeus (Ingegno et al., 2011; Lins et al., 2014), D. errans (Ingegno et al., 2013) and $N$. tenuis (Rim et al., 2015) were reported in Y-tube olfactometer studies. However, when we compared a flowering aubergine with an aphid-infested one, we recorded equal attraction, suggesting that floral resources may affect M. pygmaeus nymphs behavior. Previous studies showed that $M$. pygmaeus nymphs consumed less prey on flowering aubergine or pepper plants. This reduction was higher in aubergine than pepper plants (Maselou et al., 2014). Landis et al. (2000) showed 
TABLE 3 | Variable importance to the projection (VIP) of volatiles for the corresponding PLS-DA plots, with value more than 1.0, which can be chosen as the characteristic volatile compounds for the differentiation between treatments.

\begin{tabular}{|c|c|c|}
\hline No & Compound & VIP value \\
\hline 1 & Hexanal & 1.92 \\
\hline 2 & m-xylene & 1.92 \\
\hline 3 & Octane & 1.90 \\
\hline 4 & $\beta$-citronellene & 1.81 \\
\hline 5 & Hydrocarbon 6 & 1.70 \\
\hline 6 & $(E)$ - $\beta$-farnesene & 1.69 \\
\hline 7 & Undecane & 1.63 \\
\hline 8 & Butyl butanoate & 1.60 \\
\hline 9 & Isoborneol & 1.56 \\
\hline 10 & Geranyl acetone & 1.50 \\
\hline 11 & 2-methylbutanal oxime & 1.44 \\
\hline 12 & Butyl acetate & 1.43 \\
\hline 13 & Unknown 4 & 1.43 \\
\hline 14 & Citronellol & 1.37 \\
\hline 15 & Unknown 2 & 1.37 \\
\hline 16 & Hydrocarbon 3 & 1.35 \\
\hline 17 & Heptanal & 1.34 \\
\hline 18 & Decane & 1.26 \\
\hline 19 & $\beta$-pinene & 1.22 \\
\hline 20 & Unknown 8 & 1.18 \\
\hline 21 & Unknown 1 & 1.18 \\
\hline 22 & Linalool & 1.14 \\
\hline 23 & $(E-E)-T M T T$ & 1.11 \\
\hline 24 & $(Z)$ - $\alpha$-bermamotene & 1.08 \\
\hline
\end{tabular}

that the presence of flowering plants in agroecosystems is a conceptually simple mean to increase densities of predators and parasitoids, since several natural enemies use pollen and/or nectar as alternative food. However, increased abundance of predators and parasitoids to be of benefit for biological control, should translate into increased predation (Stephan et al., 2016). Studies on mirids have shown that habitat management could lead to higher predator abundance and as a result to higher prey consumption (Perdikis et al., 2011; Ingegno et al., 2017).

In our study, a higher number of volatile compounds were detected in the headspace of aubergine plants compared to other studies (MacLeod and Gonzales de Treconis, 1983; Van Den Boom et al., 2004; Rim et al., 2015; Darshanee et al., 2017). Terpenoids were the most abundant volatiles in all plant treatments in agreement with previous studies for different host plants (Ingegno et al., 2016; Anastasaki et al., 2018). M. pygmaeus females responded positively to compounds emitted by $T$. absoluta infested tomato plants and also to spider mite infested plants (De Backer et al., 2017; Pappas et al., 2018). In both of the above studies a different profile of induced volatiles was identified compared to our study.

The volatile blend emitted by uninfested, flowering and aphid-infested aubergine plants differed both qualitative and quantitatively. The PLS-DA analysis revealed a separation between different treatments, indicating an alteration of volatile blend on aubergine plants after aphid infestation as well as in flowering aubergine compared to uninfested aubergine plants. The loading plot shows that hexanal and $\beta$-citronellene were responsible for the differentiation of flowering aubergine plants, while the terpenoids $E$ - $(\beta)$-farnesene and $(E, E)$-TMTT as well as the nitrogen compound 2 -methylbutanal oxime for the differentiation of aphid-infested aubergines plants. These compounds isolated only in aphid-infested aubergine plants, had also a VIP value greater than 1 . The terpenoid $(E)-\beta$-farnesene isolated only from aphid-infested aubergine plants, is known to play important role as a foraging cue for aphid natural enemies (Du et al., 1998; Verheggen et al., 2007; Hegde et al., 2011). (E)$\beta$-farnesene is a well-known alarm pheromone released from aphids to warn individuals of the same species (Pickett and Griffiths, 1980), and has also been found to act as a kairomone for several aphid predators (Verheggen et al., 2008). Plants may also emit (E)- $\beta$-farnesene either constitutively (Gibson and Pickett, 1983) or inductively (Schnee et al., 2006). In our study, aphids were not exposed to any predator, which may suggest that the emission of $(E)$ - $\beta$-farnesene was emitted by the plant itself and not by aphids, though, we cannot exclude the possibility that other kind of irritation might have occurred. In addition, we did not isolate $(E)$ - $\beta$-farnesene from uninfested aubergine plants which further suggests that its emission was induced by aphid feeding. (E,E)-TMTT is related to herbivory attack (Paré and Tumlinson, 1999; Tholl et al., 2011). It has been found to be emitted by cotton (Hegde et al., 2011) and pepper plants (Moayeri et al., 2007) after aphids' infestation. In a recent study, (E,E)-TMTT emitted from T. absoluta-infested tomato plants was shown to provoke antennal responses of M. pygmaeus in a gas chromatography coupled with mass spectrometer and electroantennographic detectors (GC-MSEAD) (De Backer et al., 2017). Another compound found only in aphid-infested aubergine plants was 2-methylbutanal oxime. This nitrogen containing compound was recorded from aubergine plants infested by Spodoptera litura larvae (Rim et al., 2015) and Tetranychus urticae (Van Den Boom et al., 2004; Rim et al., 2015). Also it, was found to elicit an olfactory response and attraction of natural enemies of Lymantria dispar (McCormick et al., 2014).

In this study we demonstrated that aphid infestation induces a change in the volatile emissions of aubergine plants that influences the foraging behavior of $M$. pygmaeus nymphs. Although aubergines at their flowering stage had a distinct volatile profile both from the uninfested and aphid-infested aubergine plants, $M$. pygmaeus nymphs did not discriminate between them. These observations are in agreement with the hypothesis that insects respond to a ratio of volatiles for host recognition rather than to individual compounds (Bruce, 2015). In addition, small qualitative differences are usually more important than obvious quantitative differences in volatiles that affect insect behavior (Bruce et al., 2010). Studies on electroantennogram (EAGs) responses of $M$. pygmaeus adults exposed to volatile compounds emitted either by host or nonhost plants showed significant EAGs records in plants with very different volatile profiles and the maximum deflection values in the EAGs correlated with the concentrations of 
sesquiterpenes and alcohols (Ingegno et al., 2016). In other experiments, $M$. pygmaeus adults perceived better the entire volatile blend of Tuta absoluta-infested tomato plants than individual compounds and synthetic blends (De Backer et al., 2017).

In conclusion, our results show that $M$. pygmaeus nymphs prefer aubergine over pepper irrespectively of their host plant origin. They were also shown to prefer aphid-infested over uninfested aubergine plants. Flowering plants were shown to be equally attractive to $M$. pygmaeus nymphs compared to aphid-infested plants.. The results of our experiments may have practical implications for the application of $M$. pygmaeus in biological control programs. For example, in order to determine the appropriate time for the introduction of this mirid in the crop as a biological control agent. However, a more detailed knowledge of the role of HIPVs is desirable to better understand the behavior of M. pygmaeus.

\section{REFERENCES}

Adams, R. P. (2007). Identification of Essential Oil Components by GasChromatography/Mass Spectrometry, Fourth Edition. Carol Stream, IL: Allured Business Media.

Agresti, A. (2013). Categorical Data Analysis, Third Edition. Hoboken, NJ: John Wiley and Sons, Inc.

Anastasaki, E., Drizou, F., and Milonas, P. (2018). Electrophysiological and oviposition responses of Tuta absoluta females to herbivore-induced volatiles in tomato plants. J. Chem. Ecol. 44, 288-298. doi: 10.1007/s10886-0180929-1

Boege, K., and Marquis, R. J. (2005). Facing herbivory as you grow up: the ontogeny of resistance in plants. Trends Ecol. Evol. 20, 441-448. doi: $10.1016 /$ j.tree.2005.05.001

Bruce, T. J., and Pickett, J. A. (2007). Plant defence signalling induced by biotic attacks. Curr. Opin. Plant. Biol. 10, 387-392. doi: 10.1016/j.pbi.2007.05.002

Bruce, T. J. A., Midega, C. A. O., Birkett, M. A., Pickett, J. A., and Khan, Z. R. (2010). Is quality more important than quantity? Insect behavioural responses to changes in a volatile blend after stemborer oviposition on an African grass. Biol. Lett. 6, 314-317. doi: 10.1098/rsbl.2009.0953

Bruce, T. Jhanee HLC, Ren H, Ahmed . (2015). Interplay between insects and plants: dynamic and complex interactions that have coevolved over millions of years but act in milliseconds. J. Exp. Botany 66, 455-465. doi: 10.1093/jxb/eru391

Cai, X., Sun, X., Dong, W., Wang, G., and Chen, Z. (2014). Herbivore species, infestation time, and herbivore density affect induced volatiles in tea plants. Chemoecology 24, 1-14. doi: 10.1007/s00049-013-0141-2

Calvo, F. J., Lorente, M. J., Stansly, P. A., and Belda, J. E. (2012). Preplant release of Nesidiocoris tenuis and supplementary tactics for control of Tuta absoluta and Bemisa tabaci in greenhouse tomato. Entomol. Exp. Appl. 143, 111-119. doi: 10.1111/j.1570-7458.2012.01238.x

Castañé, C., Arnó, J., Gabarra, R., and Alomar, O. (2011). Plant damage to vegetable crops by zoophytophagous mirid predators. Biol. Control 59, 22-29. doi: 10.1016/j.biocontrol.2011.03.007

Coll, M., and Guershon, M. (2002). Omnivory in terrestrial arthropods: mixing plant and prey diets. Annu. Rev. Entomol. 47, 267-297. doi: 10.1146/annurev.ento.47.091201.145209

Darshanee, H. L. C., Ren, H., Ahmed, N., Zhang, Z. F., Liu, Y. H., and Liu, T. X. (2017). Volatile-mediated attraction of greenhouse whitefly Trialeurodes vaporariorum to tomato and eggplant. Front. Plant Sci. 8:1285. doi: 10.3389/fpls.2017.01285

De Backer, L., Bawin, T., Schott, M., Gillard, L., Marko', I. E., Francis, F., et al. (2017). Betraying its presence: identification of the chemical signal released

\section{AUTHOR CONTRIBUTIONS}

DM, PM: Conceived and designed the experiments; DM, EA: Performed the experiments; DM, EA, PM: Analyzed the data and wrote the paper; PM: Contributed reagents, materials, analysis tools; DM, EA, PM: contributed to revisions.

\section{ACKNOWLEDGMENTS}

This research has been co-financed by the European Union (European Social Fund-ESF) and Greek national funds through the Operational Program Education and Lifelong Learning of the National Strategic Reference Framework (NSRF)-Research Funding Program: Heracleitus II. Investing in knowledge society through the European Social Fund. We would also like to thank the reviewers and the editor for their constructive and helpful comments that considerably improved the manuscript.

by Tuta absoluta-infested tomato plants that guide generalist predators toward their prey. Arthropod Plant Int. 11, 111-120. doi: 10.1007/s11829-016-9471-7

De Backer, L., Caparros Megido, R., Fauconnier, M., Brostaux, Y., Francis, F., and Verheggen, F. (2015). Tuta absoluta-induced plant volatiles: attractiveness towards the generalist predator Macrolophus pygmaeus. Arthropod Plant Int. 9, 465-476. doi: 10.1007/s11829-015-9388-6

de Boer, J. G., and Dicke, M. (2006). Olfactory learning by predatory arthropods. Anim. Biol. 56, 143-155. doi: 10.1163/157075606777304221

Dicke, M. (1994). Local and systemic production of volatile herbivore-induced terpenoids: their role in plant-carnivore mutualism. J. Plant Physiol. 143, 465-472. doi: 10.1016/S0176-1617(11)81808-0

Dicke, M. (1999). "Evolution of induced indirect defense of plants," in The Ecology and Evolution of Inducible Defenses, eds R. Tollrian and C. J. Harvell (Princeton, NJ: Princeton University Press), 62-88.

Dicke, M., and Sabelis, M. W. (1988). How plants obtain predatory mites as bodyguards. Neth. J. Zool. 38,148-165. doi: 10.1163/156854288X00111

Dicke, M., Van der Maas, K. J., Takabayashi, J., and Vet, L. E. M. (1990). Learning affects response to volatile allelochemicals by predatory mites. Proceedings of the Section Experimental and Applied Entomology of the Netherlands Entomological Society, 31-36.

Dicke, M., and Vet, L. E. M. (1999). "Plant-carnivore interactions: evolutionary and ecological consequences for plant, herbivore and carnivore," in Herbivores: Between Plants and Predators, eds H. Olff, V. K. Brown, and R. H. Drent (Oxford: Blackwell Science), 483-520.

Du, Y., Poppy, G. M., Powell, W., Pickett, G. A., Wadhams, L. G., and Woodcock, C. M. (1998). Identification of semiochemicals released during aphid feeding that attract parasitoid Aphidius ervi. J. Chem. Ecol. 24,1355-1368. doi: 10.1023/A:1021278816970

Eubanks, M. D., and Denno, R. F. (1999). The ecological consequences of variation in plants and prey for an omnivorous insect. Ecology 80, 1253-1126. doi: 10. 1890/0012-9658(1999)080[1253:TECOVI]2.0.CO;2

Gibson, R. W., and Pickett, J. A. (1983). Wild potato repels aphids by release of aphid alarm pheromone. Nature 302:608. doi: 10.1038/302608a0

Greany, P. D., and Hagen, K. S. (1981). "Prey selection," in Semiochemicals: Their Role in Pest Control, eds D. A. Nordlund, R. L. Jones, and W. J. Lewis (Chichester: Wiley), 51-77.

Hegde, M., Oliveira, J. N., da Costa, J. G., Bleicher, E., Santana, A. E. G., Bruce, T. J. A., et al. (2011). Identification of semiochemicals released by cotton, Gossypium hirsutum, upon infestation by the cotton aphid, Aphis gossypii. J. Chem. Ecol. 37, 741-750. doi: 10.1007/s10886-011-9980-x

Hilker, M., and Meiners, T. (2002). Induction of plant responses to oviposition and feeding by herbivorous arthropods: a comparison. Entomol. Exp. Appl. 104, 181-192. doi: 10.1046/j.1570-7458.2002.01005.x 
Ingegno, B. L., Candian, V., Psomadelis, I., Bodino, N., and Tavella, L. (2017). The potential of host plants for biological control of Tuta absoluta by the predator Dicyphus errans. B. Entomol. Res. 107, 340-348. doi: 10.1017/S0007485316001036

Ingegno, B. L., Ferracini, C., Gallinotti, D., Alma, A., and Tavella, L. (2013). Evaluation of the effectiveness of Dicyphus errans (Wolff) as predator of Tuta absoluta (Meyrick). Biol. Control 67, 246-252. doi: 10.1016/j.biocontrol.2013.08.002

Ingegno, B. L., La-Spina, M., Jordan, M. J., Tavella, L., and Sanchez, J. A. (2016). Host plant perception and selection in the sibling species Macrolophus melanotoma and Macrolophus pygmaeus (Hemiptera: Miridae). J. Insect Behav. 29, 117-142. doi: 10.1007/s10905-016-9549-1

Ingegno, B. L., Pansa, M. G., and Tavella, L. (2011). Plant preference in the zoophytophagous generalist predator Macrolophus pygmaeus (Heteroptera: Miridae). Biol. Control 58, 174-181. doi: 10.1016/j.biocontrol.2011.06.003

Koricheva, J., and Barton, K. E. (2012). "Temporal changes in plant secondary metabolite production: patterns, causes and consequences," in The Ecology of Plant Secondary Metabolites, eds G. R. Iason, M. Dicke, and S. E. Hartley (Cambridge: Cambridge University Press), 34-55.

Landis, D. A., Wratten, S. D., and Gurr, G. M. (2000). Habitant management to conserve natural enemies of arthropod pests in agriculture. Ann. Rev. Entom. 45, 175-201. doi: 10.1146/annurev.ento.45.1.175

Letourneau, D. K. (1998). "Conservation biology: lessons for conserving natural enemies," in Conservation Biological Control, ed P. Barbosa (San Diego, CA: Academic Press), 9-38.

Lins, J. C. Jr., van Loon, J. J. A., Bueno, V. H. P., Lucas-Barbosa, D., Dicke, M., and van Lenteren, J. C. (2014). Response of the zoophytophagous predators Macrolophus pygmaeus and Nesidiocoris tenuis to volatiles of uninfested plants and to plants infested by prey or conspecifics. BioControl 59, 707-718. doi: 10.1007/s10526-014-9602-y

Lykouressis, D. P., Perdikis, D. CH., and Chaljia, F. CH. (1999-2000). The effects of natural enemies on aphid populations on processing tomato in central Greece. Entomol. Hell. 13, 35-42 doi: 10.12681/eh.14036

MacLeod, A. J., and Gonzales de Treconis, N. (1983). Aroma volatiles of eggplants (Solanum melongena). Phytochemistry 22, 2077-2079. doi: 10.1016/0031-9422(83)80049-1

Maselou, D. A., Perdikis, D. CH., Sabelis, M. W., and Fantinou, A. A. (2014). Use of plant resources by an omnivorous predator and the consequences for effective predation. Biol. Control 79, 92-100. doi: 10.1016/j.biocontrol.2014.09.002

Maselou, D. A., Perdikis, D. Ch., Sabelis, M. W., and Fantinou, A. A. (2015). Plant resources as a factor altering emergent multi-predator effects. PLOS ONE 10:e0138764. doi: 10.1371/journal.pone.0138764

McCormick, C. A., Irmisch, S., Reinecke, A., Boeckler, G. A., Veit, D., Reichelt, M., and Unsicker, S.B. (2014). Herbivore-induced volatile emission in black poplar: regulation and role in attracting herbivore enemies. Plant Cell Environ. 37, 1909-1923. doi: 10.1111/pce.12287

Moayeri, H. R. S., Ashouri, A., Poll, L., and Enkegaard, A. (2007). Olfactory response of a predatory mirid to herbivore induced plant volatiles: multiple herbivory vs. single herbivory. J. Appl. Entomol. 131, 326-332. doi: 10.1111/j.1439-0418.2007.01177.x

Moerkens, R., Berckmoes, E., Van Damme, V., Ortega-Parra, N., Hanssen, I., Wuytack, M., et al. (2016). High population densities of Macrolophus pygmaeus on tomato plants can cause economic fruit damage: interaction with Pepino mosaic virus? Pest Manag. Sci. 72, 1350-1358. doi: 10.1002/ps.4159

Moreno-Ripoll, R., Gabarra, R., Symondson, W. O. C., and King, R. A. (2014). Do the interactions among natural enemies compromise the biological control of the whitefly Bemisia tabaci? J. Pest Sci. 87, 133-141. doi: 10.1007/s10340-013-0522-x

Pappas, M. L., Liapoura, M., Papantoniou, D., Avramidou, M., Kavroulakis, N., Weinhold, A., et al. (2018). The beneficial endophytic fungus Fusarium solani strain $\mathrm{K}$ alters tomato responses against spider mites to the benefit of the plant. Front. Plant Sci. 9:1603. doi: 10.3389/fpls.2018.01603

Pappas, M. L., Steppuhn, A., and Broufas, G. D. (2016). The role of phytophagy by predators in shaping plant interactions with their pests. Commun. Integr. Biol. 9:e1145320. doi: 10.1080/19420889.2016.1145320

Pappas, M. L., Steppuhn, A., Geuss, D., Topalidou, N., Zografou, A., Sabelis, M. W., et al. (2015). Beyond predation: the zoophytophagous predator
Macrolophus pygmaeus induces tomato resistance against spider mites. PLoS ONE 10:e0127251. doi: 10.1371/journal.pone.0127251

Paré, P. W., and Tumlinson, J. H. (1999). Plant volatiles as a defense against insect herbivores. Plant Physiol. 121, 325-331. doi: 10.1104/pp.121.2.325

Perdikis, D., Fantinou, A., and Lykouressis, D. (2011). Enhancing pest control in annual crops by conservation of predatory Heteroptera. Biol. Control 59, 13-21. doi: 10.1016/j.biocontrol.2011.03.014

Perdikis, D., and Lykouressis, D. (1999). Development and mortality of nymphal stages of the predator bug Macrolophus pygmaeus, when maintained at different temperatures and on different hosts plants. Bull. IOBC/WPRS 22, 137-144.

Perdikis, D., and Lykouressis, D. (2000). Effects of various items, host plants and temperatures on the development and survival of Macrolophus pygmaeus (Rambur) (Hemiptera: Miridae). Biol. Control 17, 55-60. doi: 10.1006/bcon.1999.0774

Perdikis, D., Lykouressis, D., and Economou, L. (2004). The influence of light-dark phase, host plant, temperature, and their interactions on predation rate in an insect predator. Environ. Entomol. 33, 1137-1144. doi: 10.1603/0046-225X-33.5.1137

Perdikis, D. C. h., and Lykouressis, D. (2004a). Macrolophus pygmaeus (Hemiptera: Miridae) population parameters and biological characteristics when feeding on eggplant and tomato without prey. J. Econ. Entomol. 97, 1291-1298. doi: 10.1093/jee/97.4.1291

Perdikis, D. CH., and Lykouressis, D. P. (1997). Rate of development and mortality of nymphal stages of the predator Macrolophus pygmaeus (Rambur) feeding on various preys and host plants. IOBC/WPRS Bull. 20, 241-248.

Perdikis, D. CH., and Lykouressis, D. P. (2004b). Myzus persicae (Homoptera: Aphididae) as a suitable prey for Macrolophus pygmaeus (Hemiptera: Miridae) population increase on pepper plants. Environ. Entomol. 33, 499-505. doi: 10.1603/0046-225X-33.3.499

Pérez-Hedo, M., Bouagga, S., Jaques, J. A., Flors, V., and Urbaneja, A. (2015a). Tomato plant responses to feeding behavior of three zoophytophagous predators (Hemiptera: Miridae). Biol. Control 86, 46-51. doi: 10.1016/j.biocontrol.2015.04.006

Pérez-Hedo, M., Urbaneja-Bernat, P., Jaques, J. A., Flors, V., and Urbaneja, A. (2015b). Defensive plant responses induced by Nesidiocoris tenuis (Hemiptera: Miridae) on tomato plants. J. Pest Sci. 88, 543-554. doi: 10.1007/s10340-014-0640-0

Pickett, J. A., and Griffiths, D. C. (1980). Composition of aphid alarm pheromones. J. Chem. Ecol. 6, 349-360. doi: 10.1007/BF01402913

Rim, H., Uefune, M., Ozawa, R., and Takabayashi, J. (2017). Experience of plant infestation by the omnivorous arthropod Nesidiocoris tenuis affects its subsequent responses to prey-infested plant volatiles. Biol. Con. 62, 233-242. doi: 10.1007/s10526-017-9791-2

Rim, H., Uefune, M., Ozawa, R., Yoneya, K., and Takabayashi, J. (2015). Olfactory response of the omnivorous mirid bug Nesidiocoris tenuis to eggplants infested by prey: specificity in prey developmental stages and prey species. Biol. Con. 91, 47-54. doi: 10.1016/j.biocontrol.2015.07.009

Sabelis, M. W., Janssen, A., Pallini, A., Venzon, M., Bruin, J., Drukker, B., et al. (1999). "Behavioral responses of predatory and herbivorous arthropods to induced plant volatiles: from evolutionary ecology to agricultural applications," in Induced Plant Defenses Against Pathogens and Herbivores. Biochemistry, Ecology and Agriculture, eds A. A. Agrawal, S. Tuzun, and E. Bent (St. Paul, MN: APS Press), 269-296.

Sanchez, J. A., Gillespie, D. R., and McGregor, R. R. (2004). Plant preference in relation to life history traits in the zoophytophagous predator Dicyphus hesperus. Entomol. Exp. Appl. 112, 7-19. doi: 10.1111/j.0013-8703.2004.00174.x

Sanchez, J. A., López-Gallego, E., Pérez-Marcos, M., Perera-Fernández, L. G., and Ramírez-Soria, M. J. (2018). How safe is it to rely on Macrolophus pygmaeus (hemiptera: miridae) as a biocontrol agent in tomato crops? Front. Ecol. Environ. 6:132. doi: 10.3389/fevo.2018.00132

Schnee, C., Köllner, T. G., Held, M., Turlings, T. C., Gershenzon, J., and Degenhardt, J. (2006). The products of a single maize sesquiterpene synthase form a volatile defense signal that attracts natural enemies of maize herbivores. Proc. Natl. Acad. Sci. U.S.A. 103, 1129-1134. doi: 10.1073/pnas.0508027103

Steidle, J. L. M., and van Loon, J. J. A. (2003). Dietary specialization and infochemical use in carnivorous arthropods: testing a concept. Entom. Exp. Appl. 108, 133-148. doi: 10.1046/j.1570-7458.2003.00080.x 
Stephan, J. G., Albertsson, J., Wang, L., and Porcel, M. (2016). Weeds within willow short-rotation coppices alter the arthropod community and improve biological control of the blue willow beetle. BioControl 61, 103-114. doi: 10.1007/s10526-015-9693-0

Tholl, D., Sohrabi, R., Huh, J.-H., and Lee, S. (2011). The biochemistry of homoterpenes? Common constituents of floral and herbivoreinduced plant volatile bouquets. Phytochemistry 72, 1632-1646. doi: 10.1016/j.phytochem.2011.01.019

Tumlinson, J. H., Lewis, W. J., and Vet, L. E. M. (1993). How parasitic wasps find their hosts. Sci. Am. 268, 100-106. doi: 10.1038/scientificamerican0393-100

Turlings, T. C. J., Tumlinson, J. H., and Lewis, W. J. (1990). Exploitation of herbivore- induced plant odors by host- seeking parasitic wasps. Science 250, 1251-1253. doi: 10.1126/science.250.4985.1251

Urbaneja, A., González-Cabrera, J., Arnó, J., and Gabarra, R. (2012). Prospects for the biological control of Tuta absoluta in tomatoes of the Mediterranean basin. Pest Manag. Sci. 68, 1215-1222. doi: 10.1002/ps.3344

Van Den Boom, C. E. M., Van Beek, T. A., Posthumus, M. A., De Groot, A., and Dicke, M. (2004).Qualitative and quantitative variation among volatiles induced by Tetranychus urticae feeding on plants from various families. J. Chem. Ecol. 30, 69-88. doi: 10.1023/B:JOEC.0000013183.729 15.99

Vandekerkhove, B., and De Clercq, P. (2010). Pollen as an alternative or supplementary food for the mirid predator Macrolophus pygmaeus. Biol.Control 53, 238-242. doi: 10.1016/j.biocontrol.2010.01.005

Verheggen, F. J., Arnaud, L., Bartram, S., Gohy, M., and Haubruge, E. (2008). Aphid and plant volatiles induce oviposition in an aphidophagous hoverfly. J. Chem. Ecol. 34, 301-307. doi: 10.1007/s10886-008-9434-2
Verheggen, F. J., Schwartzberg, E., Haubruge, E., and Tumlinson, J. (2007) Emission of Alarm Pheromone in Aphids: A Contagious Phenomenon? Abstract retrieved from Abstracts in 59th International Symposium on Crop Protection, Ghent.

Vet, L. E. M., and Dicke, M. (1992). Ecology of infochemical use by natural enemies in a tritrophic context. Ann. Rev. Entomol. 37, 141-172. doi: 10.1146/annurev.en.37.010192.001041

Zappala, L., Biondi, A., Alma, A., Al-Jboory, I. J., Arno Bayram, J. A., and Chailleux, A. (2013). Natural enemies of the South American moth, Tuta absoluta, in Europe, North Africa and Middle East, and their potential use in pest control strategies. J. Pest Sci. 86, 635-647. doi: 10.1007/s10340-013-0531-9

Zhang, N. X., Messelink, G. J., Alba, J. M., Schuurink, R. C., Kant, M. R., and Janssen, A. (2018). Phytophagy of omnivorous predator Macrolophus pygmaeus affects performance of herbivores through induced plant defences. Oecologia 186, 101-113. doi: 10.1007/s00442-017-4000-7

Conflict of Interest Statement: The authors declare that the research was conducted in the absence of any commercial or financial relationships that could be construed as a potential conflict of interest.

Copyright (c) 2019 Maselou, Anastasaki and Milonas. This is an open-access article distributed under the terms of the Creative Commons Attribution License (CC BY). The use, distribution or reproduction in other forums is permitted, provided the original author(s) and the copyright owner(s) are credited and that the original publication in this journal is cited, in accordance with accepted academic practice. No use, distribution or reproduction is permitted which does not comply with these terms. 